\title{
STUDIES OF CALCIUM AND PHOSPHORUS METABOLISM. XX. THE HIGH CALCIUM EXCRETION IN EXOPHTHALMIC GOITER IS NOT DUE TO VITAMINE D DEFICIENCY
}

By DOROTHY M. TIBBETTS, REGINA McLEAN, AND JOSEPH C. AUB

(From the Medical Laboratories of the Collis P. Huntington Memorial Hospital of Harvard University, Boston)

(Received for publication June 30, 1932)

In previous publications of this series $(1,2)$, it has been demonstrated that exophthalmic goiter is associated with a calcium and phosphorus excretion elevated in excess of the increased general metabolism. Several conditions have a high urinary calcium excretion. As far as is now known, such a high calcium output when elevated in both urine and feces is found only in hyperthyroidism and vitamine $\mathrm{D}$ deficiencies (3). A patient with osteomalacia, carefully studied by Gargill, Gilligan, and Blumgart (4), showed an analogous high urinary and fecal calcium excretion, which returned to normal after large doses of vitamine D. It was, therefore, of interest to determine whether hyperthyroid cases, because of the elevated metabolic demand, could be suffering from vitamine $\mathrm{D}$ deficiencies due to an increased need for vitamines. The idea gains some support in the work of Plimmer (5) of Cowgill and Klotz (6) and of Himwich, Goldfarb and Cowgill (7), which indicates that the amount of vitamine B required by the organism is determined chiefly by its caloric requirement. In hyperthyroidism the publications of McCarrison (8) have directed attention to the relation of diet and hyperthyroidism, and Rabinowitch (9) and Fraser and Cameron (10) have published observations which suggested that the addition of vitamines $\mathrm{A}$ and $\mathrm{D}$ to iodine gave a somewhat greater improvement in Grave's disease, than did iodine alone. In the following observations, this problem was studied by giving irradiated ergosterol to hyperthyroid patients who were maintained on an otherwise constant regime.

\section{METHODS}

The same careful metabolic routine fully described in previous publications (11), was followed. Further descriptions of this technic need not be added here. The diet was essentially neutral in its acid-base contents as calculated from Sherman's tables (12). The constituents were similar to those of Table VII in paper XI of this series (13), though the total amounts were increased to conform with the caloric needs of 
exophthalmic goiter patients. Bacon, because of its varying content of sodium chloride was replaced by egg white and lactose. The calcium, phosphorus, and nitrogen contents of this diet were checked by actual analyses. The analytical methods which we used were: Titratable acidity, modified after Henderson and Palmer (14), ammonia by the permutit-nesslerization method of Folin (15), calcium and phosphorus by Fiske's methods (16), and nitrogen by the Kjeldahl method.

\section{DATA}

The two patients were carefully selected as classical examples of exophthalmic goiter. One of them (AL) had the deformity of an old bone tuberculosis with Pott's disease, but apparently this had been inactive for many years. The patients were most cooperative and regularly ate their entire diet, so that they remained on a very constant regime. The actual periods of the observations were not begun until after $\mathrm{RC}$ had rested in bed without medication for six days and AL for ten days. As a result, the basal metabolic rate remained remarkably constant throughout the study until the addition of Lugol's solution to their regime caused its usual effect. Such a steady state was obviously essential in observations such as are here recorded. Because the results were so obvious and conclusive, only two observations have been made. The collected data are shown in Table I. They again demonstrate the high calcium and phosphorus excretion which occurs in exophthalmic goiter. This high excretion was maintained, for at least four weeks, in spite of a neutral diet, a positive nitrogen balance, and complete rest for the patient. The average threeday excretion of normal individuals on a neutral diet with similar intake was found to be $572 \mathrm{mgm}$., of which $386 \mathrm{mgm}$. were fecal. In these small women the calcium excretion was, therefore, four times the normal.

The addition of large amounts of irradiated ergosterol did not diminish the urinary calcium excretion nor influence the unusually high fecal excretion of calcium. This was true even though enough was given to slightly elevate the blood calcium levels. The response here is very different from that seen in Blumgart's case (4) and in the study of Bauer and Marble (17) who showed that vitamine $D$ reduced the fecal calcium excretion dramatically in a patient suffering from steatorrhoea.

The addition of irradiated ergosterol to the diet likewise caused no significant change in the basal metabolic rate, or in the urinary excretion of ammonia or titratable acids.

In both patients, however, there was a more marked nitrogen retention associated with its ingestion.

It is, therefore, clear that the high calcium excretion found in hyperthyroidism is not due to a deficiency of vitamine $D$. 


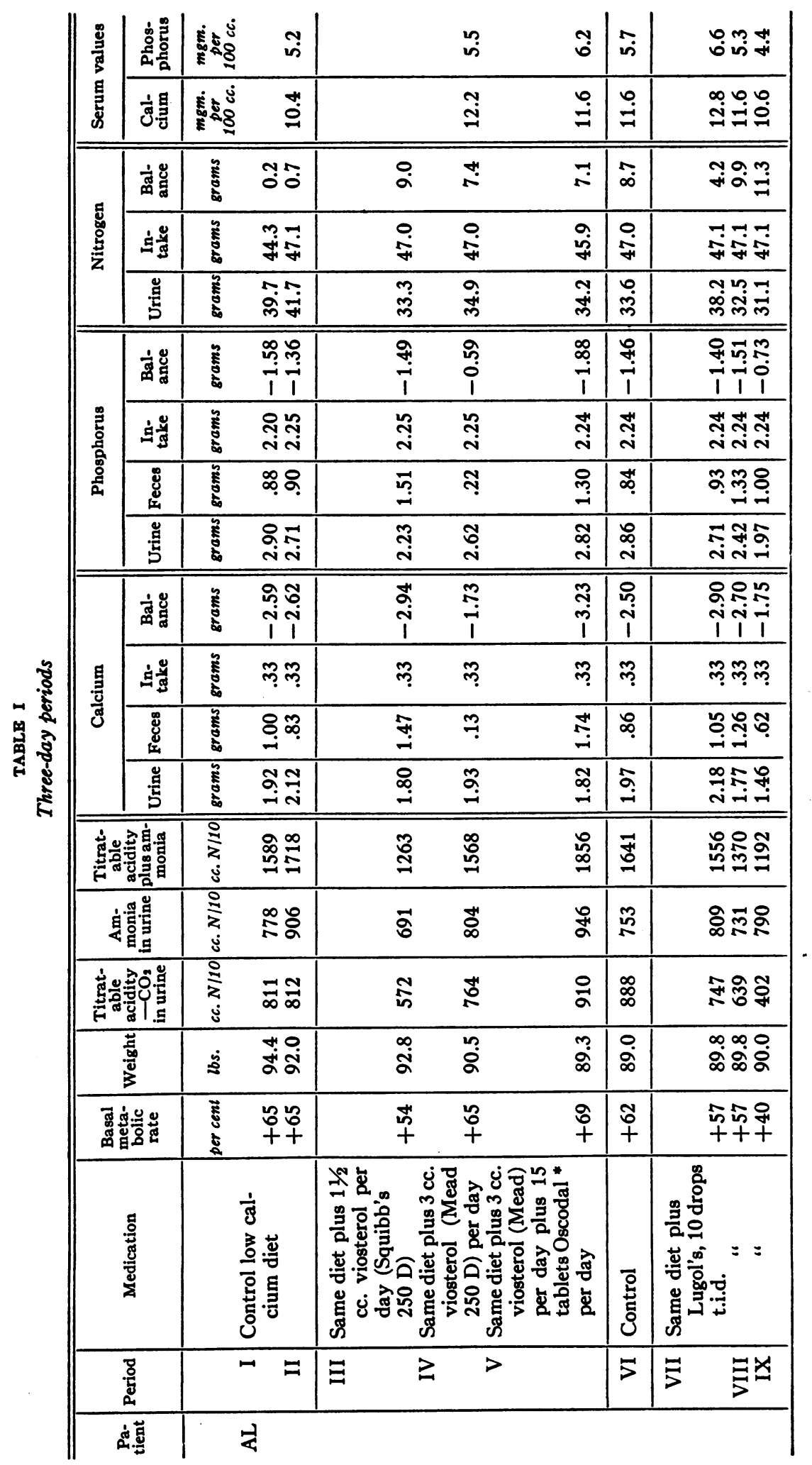




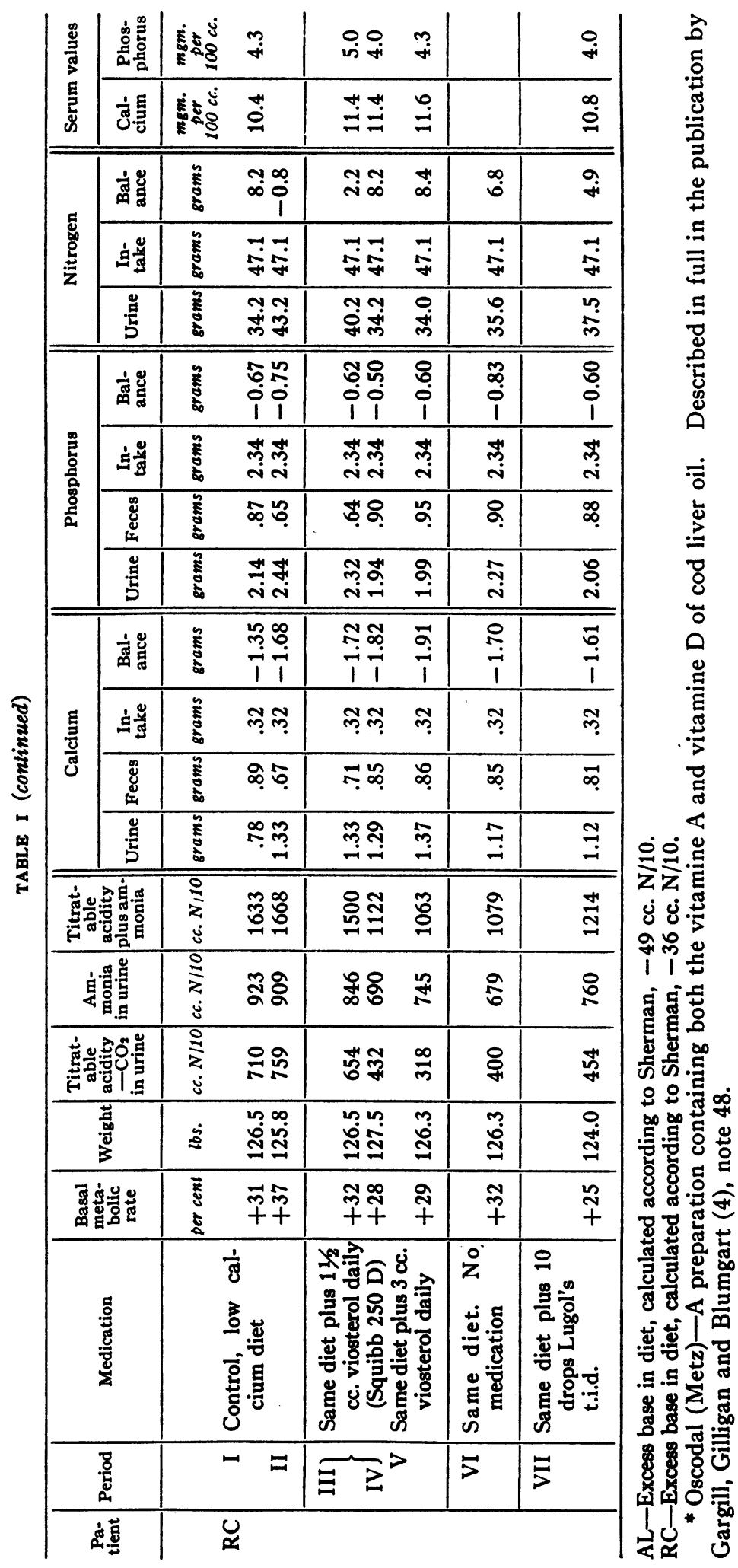




\section{PROTOCOLS 1}

Agnes L.-(M. G. H. number 252580, H. H. number 31: 145). An American housewife, aged 23, who was married four years ago, and separated from her husband after two years of married life. She has one child. Nineteen years ago she gradually developed a kyphosis which followed a severe fall. This tuberculous lesion was fused nine years ago and has remained unchanged since then. Eight months before entry, she noticed a swelling in her neck. Since then she has noticed the appearance of exophthalmos, emotional instability, easy fatigability, and excessive perspiration. She lost five pounds from her average weight of one hundred.

Physical examination showed the classical characteristics of Grave's disease: exophthalmos, tachycardia; warm, perspiring skin; marked restlessness, and fine tremor of the hands. The thyroid was universally enlarged but more markedly on the right side. A loud systolic bruit could be heard over the whole gland. The heart was not enlarged. There was a blowing systolic murmur heard along the sternum. The blood pressure was $135 / 70$. There was a marked kyphosis of the spine at about the level of the tenth thoracic vertebra. This area was not tender and very rigid.

Laboratory data: Her temperature was normal throughout the observation. Routine urine analysis was normal. The morphology of the blood showed a hemoglobin of 65 per cent $(T)$, red blood cells $3,700,000$, and white blood cells 6,700 per cu. $\mathrm{mm}$. The blood smear showed slight achromia and 41 per cent lymphocytes and monocytes.

After the studies reported in this communication, she returned to the Massachusetts General Hospital, where an uneventful, subtotal thyroidectomy was performed. Her basal metabolic rates determined since the operation have all showed normal values.

A pathological report of the thyroid from Dr. J. I. Bradley at the Massachusetts General Hospital was as follows: "The specimen consists of a mass of thyroid tissue weighing 32 grams. The tissue is homogeneous in consistency. Microscopic examination shows a marked hyperplasia of the acini which are lined by high cuboidal or columnar epithelium which protrudes into the lumen in papillomatous folds. Some of the acini are dilated and contain colloid, but there is little or no colloid in most of them.

"Hyperplasia, exophthalmic type."

Ray C.-(M. G. H. number 310305, H. H. number 30: 1485). A female American born farmer, aged 39 . For ten years she had noticed a swelling in the neck which had not increased in size. Six months before entry, during the nervous strain of unemployment, she became very nervous and lost twenty-five pounds in weight. Her eyes became prominent, she developed a marked tremor, and an increased appetite and thirst. She was very irritable and easily fatigued. One year ago she had emotional upsets when pregnant for the third time.

The physical examination showed a well developed and nourished woman. She had very marked exophthalmos and a warm, soft, moist skin. There was a marked tremor of the tongue and hand. The muscles were weak. The thyroid was somewhat irregularly enlarged, and a systolic bruit could be heard over it. The heart rate varied between 110 and 80 . The heart sounds were not abnormal. The blood pressure was $130 / 60$.

The usual routine laboratory studies of urine, feces, and blood were not

${ }^{1}$ Both of these cases were kindly referred to us from the Massachusetts General Hospital by Doctors James H. Means and J. Lerman. 
remarkable. X-rays of the chest disclosed nothing abnormal. Her temperature was normal throughout the observation.

After the studies reported in this communication, she returned to the Massachusetts General Hospital, where an uneventful subtotal thyroidectomy was performed. Two basal metabolic rates determined there showed the postoperative rate to be minus 21 per cent and minus 25 per cent.

A pathological report of the thyroid, made by Dr. J. I. Bradley at the Massachusetts General Hospital, was as follows: "The specimen weighed 110 grams. Microscopic examination showed numerous small and medium sized acini lined by high cuboidal epithelium and filled with a moderate amount of vacuolated colloid. The majority of the acini showed rather marked papillary proliferation of the epithelium. In some areas the papillary projections are so marked that the lumina of the acini are almost occluded. There is a slight fibrosis and a few focal lymphocytic accumulations are present.

"Hyperplasia, exophthalmic type."

\section{BIBLIOGRAPHY}

1. Aub, Joseph C., Bauer, Walter, Heath, Clark, and Ropes, Marion, J. Clin. Invest., 1929, vii, 97. Studies of Calcium and Phosphorus Metabolism. III. The Effects of the Thyroid Hormone and Thyroid Disease.

2. Albright, Fuller, Bauer, Walter, and Aub, Joseph C., J. Clin. Invest., 1931, $\mathrm{x}$, 187. Studies of Calcium and Phosphorus Metabolism. VIII. The Influence of the Thyroid Gland and the Parathyroid Hormone upon the Total Acid-Base Metabolism.

3. Aub, Joseph C., Calcium and Phosphorus Metabolism. The Harvey Lectures, 1928-29.

Aub, Joseph C., Proceedings of the California Academy of Medicine, 1930. The Importance of Calcium Metabolism in Internal Medicine.

4 .Gargill, Samuel L., Gilligan, Dorothy Rourke, and Blumgart, Herrman L., Arch. Int. Med., 1930, xlv, 879. Metabolism and Treatment of Osteomalacia, Its Relation to Rickets.

5. Plimmer, R. H. A., Brit. Med. J., 1926, i, 239. The Relation of the Quantity of Vitamin B to Quantity of Food.

6. Cowgill, G. R., and Klotz, B. H., Am. J. Physiol., 1927, 1xxxi, 470. Determination of the Vitamin B Requirement of the Pigeon and its Bearing on the Theory of Vitamin B Function.

7. Himwich, H. E., Goldfarb, W., and Cowgill, G. R., Proc. Soc. Exper. Biol. and Med., 1931, xxviii, 646. The Vitamin B Complex in Relation to Food Intake during Hyperthyroidism.

8. McCarrison, R., Ind. J. Med. Res., 1927, xv, 247. The Experimental Production of a New Type of Goitre, Unrelated in its Origin to Iodine.

McCarrison, R., Ind. J. Med. Res., 1928, xv, 909. Experimentally Produced Lymph-Adenoid Goitre.

McCarrison, R., Ind. J. Med. Res., 1930, xviii, 577. Further Researches on Lymph-Adenoid Goitre in Rats. Part IV.

9. Rabinowitch, I. M., Can. Med. Assoc. J., 1929, xxi, 156. The Effects of Iodine Treatment with and without Vitamins on the Basal Metabolic Rate in Exophthalmic Goitre.

10. Fraser, R. H., and Cameron, A. T., Can. Med. Assoc. J., 1929, xxi, 153. The Use of Vitamins A and D and Sodium Iodide in the Pre-operative Treatment of Graves' Disease. 
11. Bauer, Walter, and Aub, Joseph C., J. Am. Dietet. Assoc., 1927, iii, 106. Studies of Inorganic Salt Metabolism. I. The Ward Routine and Methods.

Bauer, Walter, Albright, Fuller, and Aub, Joseph C., J. Clin. Invest., 1929, vii, 75. Studies of Calcium and Phosphorus Metabolism. II. The Calcium Excretion of Normal Individuals on a Low Calcium Diet, also Data on a Case of Pregnancy.

Farquharson, Ray F., Salter, William T., Tibbetts, Dorothy M., and Aub, Joseph C., J. Clin. Invest., 1931, x, 221. Studies of Calcium and Phosphorus Metabolism. XII. The Effect of the Ingestion of Acid-producing Substances.

12. Sherman, H. C., Chemistry of Food and Nutrition, Macmillan Co., New York, 1927.

13. Salter, William T., Fulton, Constance, and Angier, Frances, J. Nutrition, 1931, iv, 1. Studies in Calcium and Phosphorus Metabolism. XI. The Calculation of Acid Base Content of the Diet.

14. Henderson, L. J., and Palmer, W. W., J. Biol. Chem., 1914, xvii, 305. On the Several Factors of Acid Excretion.

15. Folin, O., Laboratory Manual of Biological Chemistry. D. Appleton \& Co., Philadelphia, 1925, 4th ed., p. 119.

16. Fiske, C. H., and Subbarow, Y., J. Biol. Chem., 1925, lxvi, 375. The Colorimetric Determination of Phosphorus.

Fiske, C. H., and Logan, M. A., J. Biol. Chem., 1931, xciii, 211. The Determination of Calcium by Alkalimetric Titration. II. The Precipitation of Calcium in the Presence of Magnesium, Phosphate, and Sulphate, with Applications to the Analysis of Urine.

17. Bauer, W., and Marble, A., J. Clin. Invest., 1932, xi, 21. Studies on the Mode of Action of Irradiated Ergosterol. II. Its Effect on the Calcium and Phosphorus Metabolism of Individuals with Calcium Deficiency Diseases. 